\title{
RAZÓN JURÍDICA Y RAZÓN POLÍTICA EN EL PROCESO DE DESCOLONIZACIÓN DEL SÁHARA OCCIDENTAL
}

\author{
Dr. D. Francisco J. Palacios Romero \\ Universidad de Zaragoza. España
}

Analizar el conflicto del Sahara Occidental esta suponiendo acudir a dos tipos de razones: razón jurídica y razón política. Es evidente que la razón jurídica también tiene una base política, pero la diferencia está en que la razón jurídica da la legitimidad a la razón política. Una razón política sin base jurídica alguna, elusiva de normativas primarias y secundarias, o contraria a las mismas se convierte en pura y dura razón de Estado. La razón jurídica internacional fue la base de una sociedad internacional que se reclama con pretensiones de derecho, donde el primer nuevo orden internacional se lo propuso como primer objetivo (Carta de Naciones Unidas), y donde el segundo nuevo orden internacional (fin de la bipolaridad) lo articulo como una realidad incuestionable. El camino de la juridicidad en el ámbito internacional está siendo un camino compliçado entre ámbitos jurídicos de muy distinta textura. A pesar de ello ha supuesto un elemento definitivo para muchos de los avances en la consideración individual y colectiva de los derechos humanos. La normativa internacional ha chocado con muchas dificultades merced a realidades complejas sometidas a muchos intereses. Normativa internacional de carácter altamente semántico que ha ido abriéndose camino normativo en movimientos cortos pero consistentes.

La autodeterminación de los pueblos sometidos a tutelaje colonial ha sido uno de los campos más fructíferos del derecho en el ámbito internacional. Ello a pesar de existir una casuistica donde no ha operado la autodeterminación de territorios y poblaciones étnicamente coherentes sino un factor de la soberanía basado en criterios administrativos y de geografia política paracolonial. El proceso de autodeterminación del Sahara Occidental es uno de los casos en los que hay contundendencia probada a favor de la homogeneidad de territorio y población. Cuenta con el cúmulo de normativa internacional más amplio que ha existido en cualquier proceso de descolonización y autodeterminación. $Y$ no existe ningún argumento para encauzar el tema bajo el elemento de descolonización otro Estado, bajo el elemento de descolonización protegida, mediante su absorción bajo criterios de economía administrativa. Mucho menos bajo argumentos de soberanía democrática y modelo de Estado en vías de desarrollo, de los que el Estado de Marruecos no es el mejor ejemplo.

Las hipótesis manejadas en este trabajo son dos y que se deben formular, con necesidad jurídica, a modo de premisas para una conclusión contundente.

Primera: el colectivo y la población del Sahara tienen derecho al Estado por razones 
étnicas, culturales e históricas. Y por la existencia de una voluntad nacional que reivindica su hecho diferencial, el deseo de vivir y organizarse en común, la asunción de nación,cultural y su aspiración a un Estado. Esas circunstancias, y esa voluntad colectiva, están cubiertas jurídicamente como no ha existido otro caso similar en la historia de la descolonización. Es el derecho al Estado.

Segunda: el principio derecho al Estado está chocando con el hecho de la razón de Estado/s. Por ello hablar del proceso de autodeterminación del Sahara requiere hablar también de otros actores con intereses de hecho como es el caso central del Estado de Marruecos. Algunos argumentos favorables a la integración del Sahara en Marruecos utilizan el argumento político en detrimento del histórico, el cultural y el juridico. Por este argumento el Sahara debería integrarse en Marruecos por ser un Estado ya consolidado, en proceso de modernización cultural y económica y en tránsito a una democracia completa. Argumento que no resiste un mínimo análisis básico. En paralelo a Marruecos, otros Estados habrán dificultado el proceso potenciando la opción de la integración, apoyando su marco político dictatorial y persiguiendo intereses de tipo económico y geopolítico.

\section{EL ESTADO ACTUAL DE LA CUESTIÓN}

A finales del 2000 el tema ha entrado en una dificil coyuntura. En las conversaciones de Londres, de finales de Junio, y en las conversaciones de Berlín, a finales de Septiembre, Marruecos ha planteado una única salida a través de la integración y la autonomía, apoyado por la diplomacia de Francia, gran parte de la de Estados Unidos, y el laissez faire de España. El enviado especial del Secretario General de Naciones Unidas, James Baker, trabaja también con la vía integracionista. Al otro lado, el Frente Polisario, reconocido como representante de una gran parte de la población del Sahara, sólo acepta la vía jurídica de la autodeterminación, iniciada a mediados de los sesenta. El referéndum de autodeterminación es apoyado por Argelia, la mayoría de Estados de la O.U.A. y la mayoria de Estados de la sociedad internacional, como demuestran las decenas de resoluciones de la Asamblea General de N.U.

Marruecos esta manifestando una posición que niega la posibilidad de un territorio saharaui que no esté bajo su soberanía, con lo que viola explícitamente el derecho a la autodeterminación de la población saharaui proclamado en decenas de resoluciones. Y lo está haciendo con más contundencia que nunca. En base a esa posición funciona con una estrategia de dilación técnica, entorpecimiento político, confusión jurídica y colonización masiva del territorio. La fase última de esta actitud crónica se vuelve a repetir desde el comienzo de la puesta en práctica de los Acuerdos de Houston ( $2^{\circ}$ plan de paz de 1997). Esta posición no es implícita o deducida sino explícita respecto al rechazo de cualquier opción que no pase por la soberanía integra de Marruecos respecto al Sahara Occidental. La prueba más evidente son las afirmaciones de Mohamed VI en la conmemoración del 25 aniversario de la Marcha Verde donde negaba valor a toda la normativa de Naciones Unidas sobre la descolonización, se autoatribuía para Marruecos una inapelable soberanía sobre el territorio y hablaba de los planes de paz para el referéndum como vías cerradas'.

1 Aludió al proceso de descolonización como una"problemática artificial" que sólo encontrará solución "en el marco de la soberanía marroqui y de la unidad territorial" (El Murdo, 7 de noviembre de 2000). Esta actitud 
La actitud obstruccionista habría venido avalada por la actuación del Secretario General que se aparta de la vía jurídica para sugerir y ofertar lo que ha venido a denominarse vía políica. Es decir, una actitud permanentemente malintencionada, ilícita y vulneradora de derechos humanos del Estado de Marruecos -desde el comienzo del proceso (Noviembre de 1975), pasando por el frustrado Primer Plan de Paz (1991) hasta las postrimerías del Segundo Plan de Paz- se prima con el seguidismo institucional de sus tesis.

Esta actitud del Secretario General sería doblemente grave. En primer lugar por el abandono de la legalidad. La legalidad del procedimiento venía avalada por el cumplimiento de los Acuerdos de Houston. Estos Acuerdos tenían una redacción y un articulado exhaustivo que describía un complejo proceso de identificación que. era la piedra angular para el referéndum de autodeterminación ${ }^{2}$. Todas las fases se fueron cubriendo, según reconocía el Secretario General en febrero de 2000, culminando con "la publicación de la segunda parte del censo oficial provisional de votantes" y pensando ya en "la labor preparatoria para la repatriación de refugiados saharauis"'. Quedaba la última fase de los recursos. Marruecos promovió una presentación masiva de recursos que incluía a más de 130.000 excluidos, en otro último intento dilatorio. En este momento el Secretario General, y su enviado especial el exsecretario James Baker, deberian haber primado la continuación de los acuerdos, máxime teniendo en cuenta la actitud obstruccionista de Marruecos. Sin embargo se comenzaría a barajar la tesis de las dificultades ya desde casi ese mismo Informe y, fundamentalmente, a partir de los dos siguientes informes. Preconizando una nueva doctrina de tercera vía en función de calificativos y abstracciones y jurídicos indeterminados tales como "obstáculos", "diferencias entre las partes", "ninguna propuesta constructiva para avanzar".

En esta dinámica aun hay dos factores más preocupantes que se deducen de $\mathrm{S} / 2000 / 683$. El primero cuando se habla de las dificultades que han puesto las partes, haciendo una referencia directa al Frente Polisario por "no presentar propuestas concretas para resolver los múltiples problemas del plan de arreglo sobre las que las partes pudieran llegar a un acuerdo". El Frente Polisario siempre se ha ratificado en su apoyo al Plan de Arreglo y los documentos de desarrollo que solventan por si mismos todos los problemas. ¿Que puede hacer el Frente Polisario sino esperar a que la Comisión de Identificación resuelva los recursos según lo estipulado en el documento $\mathrm{S} / 1999 / 483 ?^{s}$ ¿De que nuevos acuerdos se habla? En segundo lugar la renuncia implícita al supuesto jurídico esencial del proceso de autodeterminación y la renuncia implícita al principal supuesto jurídico accidental del referéndum. Este último supuesto adosado a un nuevo principio de negociación que reitera el secretario general a instancias de la valoración de su enviado personal. La

explicitamente cerrada del nuevo Jefe de Estado, en este y otros temas, contradice las bondadosas interpretaciones políticas sobre la "nueva era".

2 Los Acuerdos de Houston vendrian avalados por el aval del Secretario General (S/1997/742).

3 En informe concluía que la Comisión de Identificación de MINURSO habia admitido a 86.386 en el censo con derecho a voto. La Comisión habia rechazado a 165.438 aspirantes (Informe S/2000/131).

4 Esta doctrina iría desarrollándose en $S / 2000 / 461$ de 22 de Mayo y $S / 2000 / 683$ de 12 de Julio.

5 Addenda al S/1999/483: "Procedimiento de apelación en relación con el referéndum del Sáhara Occidental" y "Directrices operacionales para la aplicación del procedimiento de apelación". 
negociación o el acuerdo negociado viola directamente el derecho de autodeterminación como derecho de las poblaciones que no está al arbitrio de las partes. Partes que no están legitimadas para llegar a ellos. Cuando menos en el caso del Frente Polisario que tiene un mandato vinculante de su población y de su Parlamento (Consejo Nacional Saharaui). No así en el caso de Marruecos al tratarse de un régimen autorilario gobernado por dahir'.

Lo anterior nos lleva a formular una serie de premisas. Hay una primera premisa: con el censo provisional la independencia del territorio era segura. Segunda premisa: la tesis de las dificultades para la interpretación de como sustanciar los recursos es falaz. Existen dos minuciosos documentos de la propia secretaria general sobre como desarrollar el proceso de apelación que no ofrecen ninguna clase de dudas sobre métodos y técnicas Tercera premisa: la facilidad y frivolidad con la que se ha comenzado a hablar de una salida negociada, de una tercera vía o de un acuerdo político, por encima de un proceso de autodeterminación, prescindiendo de todo un largo procedimiento jurídico, que lleva diez años en su concretización y treinta y cinco en su planteamiento general.

El presente trabajo se va a basar en el desarrollo de las premisas formuladas. Las tres premisas llevan directamente a la conclusión de la falta de voluntad política por hacer valer las razones jurídicas, favoreciendo razones políticas que, en cuanto esquivas de la legalidad, obedecen a lógicas de intereses, a lógicas de poder económicas, sociales o políticas, a lógicas de razón de Estado. Criterios de democracia, derechos humanos e imperio del Derecho han sido respetados y asumidos por una de las partes, el Frente Polisario y las doscientas mil personas por él representadas en el exilio. Por contra, este trabajo aporta los materiales suficiente como para negar el respeto a los mismos por parte del Estado de Marruecos, actitud secundada por otros actores con intereses.

Los resultandos de la coyuntura radican en que el Frente Polisario sólo aceptará la vía del referéndum; y con un calendario preciso y dinámico para el último trámite que queda por resolver como es el de los recursos. Caso de no ver una mínima voluntad en ese sentido, después de casi cuarenta años de procedimiento jurídico de descolonización, se estaría planteando la opción estratégica de la lucha armada de liberación de un territorio y una población, sometidos por el Estado de Marruecos a un estado de sitio desde hace veinticinco años?.

6 Los puntos 5,8 y 9 (S/2000/683) articulan el abandono esencial del proceso de autodeterminación y la acuñación del acuerdo negociado. Aunque el Informe es ambivalente y sigue contemplando en otros puntos la prosecución (14-18) e incluso perfeccionamiento (30) del referendum y Plan de Arreglo.

7 Véase al respecto los coınunicados del Frente Polisario después del último informe del Secretario General y la última Resolución del Consejo de Seguridad. En el mismo informaba de unas amplias maniobras en la franja liberada con participación de batallones motorizados y artillería pesada. Esta y otras referencias en hitp: www.arso.org. 


\section{MATERIALES RESPECTO AL HECHO EXTREMADA- MENTE DIFERENCIAL DE LA NACIÓN SAHARAUI}

\subsection{Geografía}

El Sahara Occidental se halla situado en el noroeste de Africa, a la altura del Trópico de Cáncer, con una superficie aproximada de $266000 \mathrm{~km}^{2}$, similar a la mitad de España. Limita al norte con Marruecos y, en una franja de 50 kilómetros, con Argelia: al este y sur con Mauritania. Su única frontera natural son sus 1062 kilómetros de costa atlántica. El resto son límites un tanto imprecisos.

\subsection{Cultura y Economía}

Los elementos que sirven para conceder la categoria de pueblo son lengua, religión, territorio y hábitos esenciales comunes, como conformadores de etnias uniformes e interrelacionadas. Desde este punto de vista los colectivos saharauis merecen la doble consideración de etnia y de pueblo.

La población es étnicamente de origen beréber con algún rasgo árabe. Tradicionalmente ha sido nómada, con una economía ganadera de casi subsistencia, completada por otras actividades como el comercio, la artesanía o la pesca. Su organización social tradicional, nunca sometida a un poder centralizado, era similar a la de otras sociedades nómadas o seminómadas. Su núcleo base es la jaima o familia, la cual formaba con otras una cabila o tribu. Cada tribu se gobernaba a través de una asamblea que elegía directamente a los jefes. A su vez los jefes reunidos conformaban otra asamblea (yemáa) que se encargaba de resolver los conflictos entre individuos o comunidades y juzgar delitos en función de una particular interpretación tradicional de la ley coránica. Con la colonización española, sobre todo a partir de 1960, llega una parcial sedentarización que hace desaparecer progresivamente la estructura social tradicional y, paralelamente, provoca conciencia de colectividad por encima de la dispersión tribal'.

El territorio saharaui es rico sobre todo en fosfatos, y también posee buenas posibilidades en hierro y gas natural. Sus bancos pesqueros son de una calidad y densidad muy elevada. Su explotación se constituye en punto clave de las negociaciones e intercambios comerciales entre Marruecos y CE-España ${ }^{10}$.

8 El concepto de pueblo es fundamental para tener un acceso directo a derechos juridicamente institucionalizados en la comunidad internacional. Es dificil cuales y cuantos deben ser los rasgos diferenciales para merecer tal consideración. La antropologia mantiene un acuerdo básico en los caracteres de la etnia compuestos por lengua, religión, territorio y hábitos esenciales. El elemento que termina por cerrar el círculo es el de una genealogía histórica propia que asignará la consideración de pueblo (Cfr. J. DUVIGNAUD, Le Langage perdu, Paris, 1973).

9 Cfr. J. CARO BAROJA, Una visión elnológica del Sahara español, Madrid, 1955.

10 J. MORILLAS, Sahara Occidental. Desarrollo y subdesarrollo, Madrid, 1995. 


\subsection{Historia}

La Historia individualiza a un colectivo. Colectivo que ha vivido durante generaciones una misma sucesión de sucesos, interactuando con otros colectivos diferenciados. Es el caso saharaui.

La colonización española del territorio comenzaría en 1884 y finalizaría en 1975 con la entrega administrativa del territorio a Marruecos en los Acuerdos de Madrid. Hasta 1884 ninguno de los distintos reinos o sultanatos -que ocupaban, grosso modo, el actual territorio de Marruecos, desde el siglo VII- pudo asentar poder y dominio sobre el desierto saharaui. Unicamente estuvo integrado todo el Sahara en un amplio imperio desde la conquista y unificación que desarrollarían los almorávides. Clanes surgidos desde el propio Sahara que consolidan un imperio desde Badajoz hasta el Níger. Es un momento en el que todo un amplio territorio, que incluye el Magreb, esta unificado bajo un poder imperial. Pero este poder no procede de Marruecos sino, más bien al contrario, procede de los clanes del desierto que integran a los propios sultanatos de Märuecos."

Como en el caso extremo de la creación del imperio Almorávide, la conformación étnica en el Sahara se produce por reunión y fusión de tribus. Y desde la desintegración del imperio la única simbiosis acusada se dio con la irrupción de tribus árabes, que no representan a sultanato alguno, sino al revés: huyen del sultanato merínida ${ }^{12}$. Por lo que la arabización del desierto no se produce por la conquista de ningún sultanato. Por lo demás no hay sino diversas incursiones y saqueos esporádicos. Hay nombramientos de delegados militares mucho más ficticios que reales. $O$ hay combates permanentes con las tribus saharauis a las que nunca someten ni se ponen bajo ningún poder establecido. En todo caso se conforma: 1) una ruta comercial que produce relaciones e intercambios comerciales 2) una red ocasional de vínculo político que: a) en ningún caso afecta a los territorios de Saguia el Hamra ni Río de Oro; b) tampoco comprometía la soberanía de los emiratos de lo que ahora es Mauritania o Malí; c) las propias tribus marroquies del Sus o Nun no estarían sometidas a los sultanatos; $d$ ) incluso muchos de los ámbitos tribales sometidos a sultanatos mantenian niveles de autonomía política y económica elevados. En la cultura tribal de todo el Magreb no se concebía otra forma de autogobernarse que no fuera la de la asabiya o formulación de democracia asamblearia. Progresivamente algunas tribus quedarían asimiladas, o serían absorbidas, merced a lo que lbn Jaldun denomina un proceso de desintegración en función de la mercantilización, incipiente burocratización y final asimilación o sujeción (umran hadari). Sin embargo, todas las conformaciones tribales Sahara, incluido el territorio que nos ocupa, se mantienen en una estructura comunitaria (umram badui ${ }^{13}$.

11 El imperio almorávide tuvo su origen en las cofradías agrupadas por lahia ben Ibrahim que precisamente se expansionan desde Río de Oro.

12 El caso concreto de la facción tribal árabe de los Beni Hassan de los Maquil que se integran en el ámbito sahariano de mayor procedencia beréber.

13 Los emiratos guardan relación de ayuda, comercio o colaboración militar, que no supondria ningún tipo de sometimiento ni cesión de soberanía. De la misma manera el poder no se ejercía siquiera respecto a tribus que se decian integradas al norte del desierto por la concreta estructura política de estas comunidades cercana al 
La libertad y autonomía política de esas poblaciones es un hecho hasta la llegada de la potencia colonial española en 1884, no consumada hasta 1934 con su implantación en Smara y Daora. España asumiría su condición colonial sobre el Sahara a través del pacto y el compromiso, estableciendo tratados de protectorado con las diversas tribus ${ }^{14}$.

En este sentido hay preguntas clave: ¿por que Marruecos llevó a cabo su lucha de independencia prescindiendo del territorio del Sahara donde no pudo convocar ni comprometer a un soblo grupo de saharauis? Sería dificil de entender que las propias fuerzas de resistencia anticolonial marroquíes no quisieran apoyo de otros territorios a los cuales se creían con derechos históricos. ¿O bien habría que deducir que ni siquiera se planteaban la más mínima reivindicación? Por otro lado si se planteaban alguna reivindicación ¿por que no consiguieron el más mínimo apoyo de las tribus que habitaban esos territorios? Sin embargo, a partir de su independencia en 1956, Marruecos comienza una politica expansionista que le lleva a infiltrar grupos armados vinculados a su ejercito. Grupos que atacan puestos franceses de Mauritania y los enclaves de Ifni y Sahara intentando subvertir a sus poblaciones, sin conseguir ningún objetivo. Las únicas acciones internas de protesta y reivindicación de independencia son internas y se plasman en los numerosas manifestaciones de disidencia acaecidas desde 1970. La represión (incidentes de junio) sin ningún movimiento español hacia proyectos de independencia conduce a la creación del Frente Polisario (Frente Popular para la liberación de Saguia el Hamra y Río de Oro) en 1973. En 1974 se elabora un proyecto de autonomía para el Sahara que contemplaba un Consejo de Gobierno saharaui, y que suponía una primera fase en el proceso de independencia. Incluso el PUNS, un partido creado por Arias Navarro para contrarrestar al Frente Polisario, firma un acuerdo de unidad de acción con éste el 12 de octubre de $1975^{13}$.

Sin embargo Marruecos dispondría de una serie de materiales para volcar el proceso en su favor, y que aun no han sido debidamente esclarecidos. Materiales que sólo se pueden basar en: ‘a) el chantaje geopolítico respecto a potenciales aciones militares tanto en el Sahara como respecto a Ceuta y Melilla; b) el chantaje ideológico respecto a la inestabilidad de un Sahara independiente; c) oscuras motivaciones de tráfico de intereses personales.

asambleismo tribal y alejadas de pleitesias al sultanato. En el Magreb cada ser formaba parte de la tribu. Mantenimiento de los lazos comunitarios tribales, enlazados por la propia vivencia del islam, lo que impedia la evolución hacia un sistema feudal o señorial clásico. Y esto es válido para todos los sucesivos reinos, cuyas únicas posibilidades de dominación se reducían, en los casos más acentuados, a una lene política fiscal, en torno al iqra. La formación de noblezas estables e institucionalizadas seria imposible, al ser hecho generalizado la asunción del papel guerrero, y asi no poder existir una casta segregada de guerreros. La problemática intertribal conllevaria en ocasiones una jerarquización en el ritmo de hegemonias colectivo, pero nunca marcaria unas diferencias de estratificación en grupos internos. Lo dicho vale para todas las grandes dominaciones de la zona (Fatimida, Almorávide, Almohade, Merinida.....Otomano). El himaya seria la otra modalidad de interdependencia, que ya daba derechos sobre tierra y jurisdiccionales sobre personas, siempre limitados por la tradición coránica. Para todo el tratamiento exhaustivo de éstas es esencial la obra de IBN JALDUN, fundamentalmente Los Prolegómenos. Aunque lbn Jaldún fue un contemporáneo del s.XIV, se dotan de vigencia las estructuras básicas descritas hasta la llegada de la ruptura colonialista decimonónica (Cfr. C.A. JULIEN, Histoire de l'Afrique du Nord; M. BLOCH, La sociéte Féodale. La formation des liens de dépendence).

14 R. CRIADO, Sahara. Pasión y muerte de un sueño colonial, Paris, 1977.

15 F. VILLAR, El proceso de autodeterminación del Sahara, Valencia, 1982. 
Todo ello tiene como resultado los Acuerdos de Madrid por los que se transfería la administración del territorio a Marruecos y Mauritania ${ }^{16}$.

Esto supuso la ocupación militar del territorio por parte del régimen marroquí ya de forma permanente. Paralelamente más de la mitad de la población huiría hacia la zona argelina de Tinduf, como exiliados, estableciéndose en la hamada de Tinduf, la parte más dura del desierto. El resto de la población saharaui quedaba bajo la administración militar de Marruecos en un estado de sitio y de guerra permanente, y con las libertades y derechos fundamentales prohibidos. Desde 1975 son 25 años de exilio, por un lado, y de ocupación militar por otro. Y desde ese momento Marruecos considera delictiva cualquier pertenencia al Frente Polisario o cualquier opinión a favor de la autodeterminación del Sahara.

Desde esa fecha los distintos gobiernos españoles -franquismo, UCD, PSOE y PP- han estrechado sus relaciones con Marruecos contemporizando con su dictadura y manteniendo un aislamiento casi total respecto a los representantes saharauis. Desde esa fecha el Frente Polisario comienza una resistencia armada hasta el alto el fuego de $1991^{17}$.

\section{LA NACIÓN POLÍTICA R.A.S.D.: DEMOCRACIA Y DESARROLLO}

La población saharaui exiliada se organizaria en torno al Frente Polisario, instauraría unos campamentos y se constituiría en población refugiada, manteniendo una organización social comunitaria ejemplar, en la línea evolucionada de lo que significaron durante siglos la institución de la asabiya y el ciclo de iumran badui teorizados por Ibn Jaldun. La comunidad de bienes y la organización asamblearia la hacen uno de los modelos de organización social más perfectos que se pueden referenciar, en medio de las dificultades de lo que no son sino campos de refugiados. La organización asamblearia y por comités se realiza a través de una organización política. Esta organización, Frente Polisario, no configura un partido único al estilo autoritario -como ha afirmado algún politólogo y algún expresidente del gobiernosino que al carecer de Estado efectúa las veces de entidad politica y base administrativa. Lo que no quita para que dentro de esa organización administrativa se reconozcan todas las tendencias ideológicas posibles. De hecho es lo que sucede tanto para la elección de la dirección en dairas (distritos) y wilayas (ciudades-campamento) como para la elección al Consejo Nacional Saharaui que hace las veces de cámara legislativa. Se puede hablar de democracia en condiciones muy dificiles

Modelo de organización política que tiene continuación en la vertiente social con una total escolarización y alfabetización de su población. La administración sanitaria comprende varios ambulatorios y un hospital central. La organización se completa con centros de telecomunicaciones y emisores de radio y televisión. El modelo educativo tiene su continuación en el envio de cientos de jóvenes a universidades extranjeras. Asi el Frente Polisario

16 Cfr. J. DIEGO AGUIRRE, Historia del Sahara español, Madrid, 1988, pp. 761-779; es la crónica histórica más completa sobre el Sahara occidental.

17 M. BARBIER, Le conflict du Sahara occidental, Paris, 1982, pp. 176 y ss. 
dispone de médicos, ingenieros o economistas formados en universidades de Argelia, España, Italia o Cuba. Se puede hablar de desarrollo a niveles muy superiores a los de cualesquiera pais del continente.

La organización militar es otro vector. La organización político-civil del Polisario se completa con una estructura militar, inevitable, como material de negociación y presión en una lógica de las relaciones internacionales basada todavía mucho más en relaciones de poder que en coordenadas jurídicas y de derecho. Desde los campamentos comenzaria la resistencia armada contra la ocupación (1975-1991) y desde alli se convertińa una guerrilla, con medios precarios, en un ejercito organizado. A pesar de su radical inferioridad armamentística y en recursos humanos, el Ejercito de Liberación Popular Saharaui, efectuaría una dificil e inédita guerra de guerrillas, siendo capaz de derrotar al ejercito marroquí, que se mostraria incapaz de desalojarlo de sus posiciones. La práctica totalidad de sus hombres permanecen movilizados militarmente en la franja de los "territorios liberados".

\section{LA CONTUNDENTE CONDICIÓN JURÍDICA A FAVOR DE LA AUTODETERMINACIÓN}

Jurídicamente el derecho de un pueblo a constituir un Estado propio tiene una base esencial. Es núcleo constitutivo de la actual sociedad internacional de la mano del Art. 1 de la Carta de Naciones Unidas ${ }^{18}$. Tema en el que inciden, de forma contundente, las resoluciones 1514 (XV) y 2625 (XXV) dedicadas a articular el derecho a la autodeterminación de los pueblos colonizados ${ }^{19}$. Las poblaciones saharauis, en función de todos los elementos histórico-culturales mencionados, entraban de lleno en los marcos de las dos resoluciones. De esa manera lo lleva reconociendo Naciones Unidas, cuya primera resolución sobre su descolonización data de $1965^{20}$. Sería al año siguiente cuando se adopta una segunda, ésta ya exhortando a la puesta en práctica de un proceso de autodeterminación, en conformidad con las aspiraciones de la propia población del territorio ${ }^{21}$. Situación que no conoce un año, desde 1965, sin Resolución de N.U. sobre su proceso de autodeterminación pendiente, exceptuando 1971. Es decir más de treinta resoluciones de Naciones Unidas a favor de un proceso de autodeterminación.

Año el de 1971 en el que precisamente será el Tribunal Internacional de Justicia quien proclame universalmente aplicable el derecho de autodeterminación a los territorios no autónomos ${ }^{22}$. Categoría claramente aplicable a las poblaciones saharauis en cuanto a su esta-

18 Siempre es útil recordar como el párrafo segundo del Art. $1^{\circ}$ de la Carta de las Naciones Unidas, es consagrado al propósito que aboga "por el derecho a la libre determinación de los pueblos". Tema en el que abundarian los arts. 2 y 55 .

19 Fundamentalmente la 1514 en referencia a los territorios no autónomos.

20 Resolución de la Asamblea General 2072 (XX). Muy anterior a la efectuada para otras decenas de Estados, sometidos a fideicomisos y en siluaciones mucho más complejas $y$, sin embargo, independientes desde hace ya décadas (cfr. el caso de Namibia con una concreta primera resolución en 1968: A.G., Res. 2.372 (XXII).

21 Resolución de la Asamblea General 2229-XXI.

22 Doctrina del T. I.J., dada en función de la casuistica sobre Namibia, en dictamen de 21 de junio de 1971 (I.C.J., Report, 1971, p. 16 y ss; C.I.J., Recueil, 1971, p. 46). 
tus internacional. Y no sólo en función de las consideraciones históricas y etnológicas anteriormente expuestas, sino por la propia jurisprudencia que emitiria el T.I.J. respecto al caso concreto, cuatro años después, en $1975^{23}$. Este dictamen, de la más alta instancia de justicia internacional, niega tajantemente vínculos de soberanía territorial del Sahara con el actual Estado de Marruecos y respecto a cualesquiera de sus anteriores sucedáneos históricos. El párrafo 162 del dictamen consultivo afirmaría que: "Los materiales e informaciones proporcionados al Tribunal no establecen la existencia de ningún vínculo de soberanía territorial entre el Sahara occidental, por una parte, y el reino de Marruecos o el conjunto mauritano, por otra. Por tanto, el Tribunal no ha comprobado la existencia de vínculos jurídicos de tal naturaleza que puedan modificar la aplicación de la resolución 1514 (XV), en cuanto a la descolonización del Sahara occidental $y$, en particular, la aplicación del principio de autodeterminación..."24.

El tema del Sahara Occidental, a finales de 1975, tenía:

a) dos resoluciones generales que obligan a una descolonización general;

b) más de diez resoluciones concretas que instan a una descolonización específica;

c) una sentencia de La Haya que, a mayor abundamiento, califica al Sahara de territorio no autónomo, concediendo virtualidad a la nación saharaui y rechazando la solicitud de Marruecos sobre la calificación de terra nullius.

Sobre esa legalidad inapelable, España firma con Marruecos y Mauritania los Acuerdos de Madrid. Por ellos España cede sus responsabilidades y poderes como administradora del territorio. Acuerdos ilegales ya que como territorio no autónomo había adquirido una consideración jurídica internacional propia separada de la disposición soberana del Estado español, por lo que este no podía ejercer movimiento alguno que no condujera a su descolonización, y mucho menos traficar con el territorio, los recursos económicos y una población ${ }^{25}$. Los Acuerdos se efectúan evitando un primer plan de paz delineado por el entonces secretario general Waldheim. Los Acuerdos intentarian adquirir un tono mayor de legalidad (sin ser citados), amparados bajo la ley 40/75, denominada Ley de Descolonización. Instrumento jurídicamente aberrante que: a)infringía el propio marco internacional; b)desmentía situaciones de hecho y de derecho como la no pertenencia del Sahara al territorio nacional y c) autorizaba al gobierno a adoptar las medidas pertinentes para la descolonización, cuando el propio gobierno ya las había tomado cinco días antes, en secreto, y no precisamente en la vía de la descolonización del territorio ${ }^{26}$.

23 Resulta importante señalar que seria el propio Estado de Marruecos el que solicitaría el mencionado dictamen. La pobreza de su material contrastaria con el rigor y exhaustividad que presentaría el material archivado por la diplomacia española, muy a pesar del gobierno Arias (Informations et documents que présente le Gonvernement espagnol à la cour conformément au deuxieme para graphe de la resolution 3292 (XXIX) de l'Assamblée Générale des Nations Unies (Libros I y II, más libro de mapas), Madrid, 1975, cit. por J. DIEGO AGUIRRE, op. cit., p. 713.

24 COUR INTERNATIONALE DE JUSTICE, Sahara Occidental. Avis consultatif, 1975.

25 En virtud de toda una clásica serie de disposiciones generales al respecto. Vid. Carta de N.U., cap. XI; Resoluciones $648,742,1541$.

26 Ley de 19-11-1975 (BOE, 20-11-1975). 
Durante todos los años siguientes no habrá un solo año sin resolución de la Asamblea General, recordando la obligación de descolonizar. Posición jurídica a la que se sumarian otros organismos internacionales e instituciones como la Organización para la Unidad Africana o el Tribunal Internacional de los Pueblos, que condenarian la ocupación militar y apoyarian un proceso de autodeterminación, reconociendo la existencia de la República Arabe Saharaui como Estado. La $19^{a}$ cumbre de la Organización para la Unidad Africana reunida en Addis Abeba, a 11 de junio de 1983, vuelve a exigir la celebración del referéndum, recordando el compromiso de Hassan II de aceptarlo, y pidiendo a Naciones Unidas la instalación de una misión de paz en el Sahara ${ }^{27}$. La OUA en 1984 admitiría a la República Arabe Saharaui Democrática (RASD) como miembro de pleno derecho. En ese momento habia sido reconocida como Estado por setenta y dos Estados.

Sin embargo, el estímulo jurídico y político de organizaciones y Estados -en un quórum dificilmente repetible- no consigue que durante quince años (1975-1990) hubiera algún tipo de impulso ni por parte de los miembros permanentes del Consejo de Seguridad, ni por parte de España, para llevar a cabo la descolonización. Sólo el coste para la inestabilidad de la zona que estaba teniendo la guerra entre el Frente Polisario y Marruecos fuerza la activación del proceso ${ }^{28}$.

\subsection{Primer Plan de Paz}

El Plan de Paz se elabora a partir de un primer documento elaborado por el Secretario General de Naciones Unidas y el Presidente de la OUA ${ }^{29}$. El mismo documento tiene un plan de aplicación más concreto que marcaria con detenimiento todos y cada uno de los elementos y de las fases (cronología general, representante especial, Minurso, cese el fuego, desmilitarización, excarcelación presos políticos, regreso de refugiados, comisión de identificación... $)^{30}$. El Consejo de Seguridad ratificaría y avalaría todo el Plan de Paz el 29 de abril de 1991 en una primera resolución de potencial eficacia directa y con un plan ejecutivo trazado ${ }^{31}$.

27 Resolución AHG/Res. 104 (XIX).

28 La Asamblea General, desde 1965, había elaborado más de veinte resoluciones instando a la descolonización, las últimas en contra de la invasión marroqui y a favor de la autodeterminación.

29 Propuesta conjunta del Secretario General de Naciones Unidas y el Presidente de la Asamblea de Estados de la OUA, en conformidad con las resoluciones 1514 (XV), 40/50 (1985) y la Resolución AHG/Res. 104 (XIX) de la OUA (La situación relativa al Sahara Occidental, Informe del Secretario General, Doc. S/21360, 18 de junio de 1990).

30 Plan de Aplicación propuesto por el Secretario General de conformidad con la Resolución 621 (1980) del Consejo de Seguridad (La situación relativa al Sahara Occidental, Informe del Secretario General, Doc. $\mathrm{S} / 21360,18$ de junio de 1990).

31 Resolución 690 (1991). Podría sospecharse que a rebufo político y estético de las fulminantes resoluciones $660,662,664,665$ que ponian en marcha, de forma extremadamente acelerada, toda la maquinaria de guerra occidental contra Irak por ocupar militarmente el territorio de Kuwait. Valdria la pena recordar como Kuwait fue un apéndice desgajado para su independencia del protectorado británico, de forma artificial, de lo que habia sido una unidad histórico-cultural inapelable. A Kuwait de Irak sólo le diferenciaba la concentrada riqueza de su subsuelo a explotar por las distintas multinacionales. 
El detallado Plan de Paz, sostenido por todo un arsenal jurídico internacional, será vulnerado y desactivado en toda su extensión. En los días marco del Plan de Paz -6/9/91 y 22/11/92- no se cumplen ninguna de las condiciones dictadas. Ni el "representante oficial de Naciones Unidas detenta la autoridad en el territorio", ni se produjo "liberación de presos y detenidos políticos", ni se efectuaría el "despliegue total de la Unidad Militar y de la Unidad de Seguridad", ni "la policía marroquí sería neutralizada", ni "el ejercito marroquí se reduciria a 65.000 hombres acuartelados en el muro", ni comienza la "repatriación de votantes y sus familias a los centros de acogida", ni "se publica lista alguna de votantes", ni se valora informe alguno de la Comisión de identificación"..... Ninguna de las circunstancias se ha cumplido, ni se ha hecho cumplir a Marruecos como potencia ocupante.

El obstruccionismo de Marruecos se vería recompensado con la falta de acción del Consejo de Seguridad ante la interpretación maximalista de Marruecos para introducir supuestos individuos con derecho a voto. La base pactada del censo español de 1974 quedaría desbordada con la nueva pretensión de Marruecos por introducir decenas de miles de individuos a identificar que en nada se podian relacionar con el exhaustivo censo realizado por España ${ }^{32}$. Marruecos se negó a publicar en los territorios ocupados la lista provisional de votantes elaborada por la Comisión de identificación. Simultáneamente intentaba introducir ciento sesenta mil nuevas personas ${ }^{33}$.

Esta situación sería contestado contundentemente por el Frente Polisario, denunciando todas las irregularidades y dilaciones consentidas. La consecuencia es todas esas circunstancias unidas a la sanción del Informe de Pérez de Cuellar por parte del Consejo de Seguridad "provoca directa o indirectamente el retorno a la guerra" a la guerra pero sí la paralización del referéndum, durante varios años utilizados por Marruecos para: a)emprender una política de colonización demográfica activa, y b)ejercer presiones económicas, políticas y prebendatarias en el exterior para favorecer su posición y debilitar las del Frente Polisario.

El obstruccionismo al Plan de Paz se efectuaría con la prepotencia y la extensión que recogerían los dos nada sospechosos informes del nuevo Secretario General Butros Ghali ${ }^{35}$. Informes que hablan de las 174 violaciones de alto el fuego por parte de Marruecos, contra las 7 del Frente Polisario, la restricción en la libertad de circulación de las propias fuerzas de la MINURSO, las graves dificultades para proporcionar a estas alojamiento, agua, alimentos y combustible. Así como la inaudita situación de que los más elementales equipos logísticos para un despliegue de fuerzas mayor llevara un año paralizado y requisado por las autoridades marroquíes (sic). Además, la pertinaz negativa marroquí a colaborar en el pro-

32 Censo realizado con mucha minuciosidad y en colaboración con los propios dirigentes tribales (Vid. Gobiemo General del Sahara. Servicio de Registro de Población, Censo y Estadistica, Censo 1974, cit. en J. DIEGO AGUIRRE, op. cit., pp. 602-642).

33 En su mayoría se pretendia integrar poblaciones de la provincia de Tarfaya, transferidos al entregar España dicha provincia del antiguo protectorado. Las tesis de Marruecos habrian sido asumidas parcialmente por el Secretario General Pérez de Cuellar una semana antes del cese de su mandato (Informe S/23299).

34 Advertía el Frente Polisario en Objeciones del Frente Polisario al Informe S/23299 del Secretario General.

35 Informes del Secretario General, Doc. S/23662 y S/24040 (28 Febrero y 29 Mayo de 1992). 
ceso de identificación, oponiéndose "a las instrucciones para la Comisión de Identificación". Testigos directos como los representantes del Comité de Identificación de Minurso o informes del propio Senado estadounidense ratificarian toda la serie de maniobras obstruccionistas. Lo más grave es que se impediría que los testimonios más duros se hicieran explícitos, como cuando se le impidió declarar al segundo jefe de la Minurso y diplomático estadounidense, ante la Cuarta Comisión de la Asamblea General, sobre las múltiples irregularidades ${ }^{36}$.

\subsection{Segundo Plan de Paz}

Podemos hablar de una segunda fase en la que el Frente Polisario, aceptaria negociar un segundo plan de $\mathrm{paz}^{37}$. Este segundo plan de paz se hará sobre la base de una final aceptación de las pretensiones de Marruecos para introducir en el proceso de identificación decenas de miles de candidatos. Fueron negociaciones directas entre Marruecos, el Frente Polisario y el enviado especial del Secretario General (Kofi Annan, 1997), James Baker. Las negociaciones dieron como resultado un nuevo Plan con un nuevo calendario ${ }^{38}$. Tiene concreción en un nuevo "Informe del Secretario General sobre la situación relativa al Sahara Occidental", donde se realiza, una vez más, un calendario concreto que señalaba diciembre de 1998 como fecha para el referéndum. Sufriendo una posterior modificación para diciembre de 1999. Y finalmente una tercera a julio del $2000^{39}$.

Los Acuerdos de Houston contemplaban que las tareas de la Comisión de Identificación de votantes concluyeran a finales de mayo de 1998. Durante los cinco meses siguientes abrir un proceso transitorio donde se diera: a) repatriación de los refugiados saharauis b) acantonamiento de las tropas marroquies que deben ser reducidas a 65.000 , a confinar en los lugares previstos c) amnistía para los detenidos políticos saharauis y prisioneros de guerra.... ${ }^{40}$.

Nuevamente ninguno de estos elementos pudo ser cumplido por la actitud de Marruecos de presentar numerosos candidatos al censo, y que teóricamente pertenecían a las agrupaciones tribales problemáticas. Estas agrupaciones tribales (H41, H61, J51, J52) apenas tenían presencia en el censo español, y su código aparece en el censo español a títu-

36 Véase el Informe adjunto de la Oficina de Servicios de Supervisión Interna sobre denuncias e irregularidades efectuadas por Frank Ruddy, exvicepresidente de la Comisión de Identificación de las Naciones Unidas. F. Rudy señalaría directamente a Marruecos como culpable de "haber manipulado la operación del referíndum", tal y como ya había señalado ante el Congreso de Estados Unidos. Alegaciones que habian sido transcritas en sendos documentos (Cfr. Examen e la eficiencia del funcionamiento administrativo y funanciero de Naciones Unidas, Nota del Secretario General, Doc. A/49/884, de 5 de abril de 1995; Investigación de denturcias de irregularidades y mala administración de la Minurso, A/Dec. 49/488, de 20 de julio de 1995).

37 Memorándum de mayo de 1996, transmitido al Secretario General (Doc. S/1996/366).

38 Conocido como los Acuerdos de Houston, firmados por ambas partes. Reconocidos en informe del Secretario general $S / 1997 / 742$.

39 Doc. $S / 1997 / 882$ (13 de noviembre de 1997).

40 Según resultados de la segunda, tercera y cuarta ronda de conversaciones. Reproducidos en Doc.S/1997/742, de 24 de septiembre de 1997, anexos I,II,III. 
lo indicativo de la presencia simplemente indiciaria de estas fracciones" ${ }^{41}$. Presentación que chocaba con lo pactado en Houston sobre la base de no patrocinar directa o indirectamente a ninguna persona de dichas agrupaciones tribales no registradas en el censo español o que no fuera familiar directo de las que sí aparecen. Marruecos apoyó e incluso transportaría a miles de personas no convocadas por la Comisión de Identificación. Incluso en una vulneración más extrema, desde el Ministerio del Interior, se crearian centros de adiestramiento para la identificación ${ }^{42}$.

Cuando el Secretario General emitió su informe S/1999/483, donde se aceptaba la identificación de los conflictivos grupos tribales, mantenía la esperanza de que "el proceso de identificación no se transforme en una segunda tanda de identificación de todas las solicitudes que han sido consideradas sin derecho a votar". Eso finalmente ocurrió así en la identificación de las tribus conflictivas, lo que dilató el proceso sobremanera. Finalmente esta situación se ha vuelto a repetir al acabar la definitiva identificación, ya que todos los individuos no aceptados han sido recurridos. El Frente Polisario hizo saber su malestar al poderse interpretar como acto claro de mala fe el agotar el sistema de recurso absolutamente en todos los casos. No obstante, y a sabiendas que esto retrasaba nuevamente la última fecha de julio del 2000, aceptó sustanciar los recursos. Con lo que daba una vez más prueba de una inagotable buena fe. Resulta inquietante, por tanto, que las potencias implicadas como Francia, España y Estados Unidos y el propio Secretario General estén lanzando la posibilidad de una llamada tercera via. La tercera vía supone saltarse todo el proceso de autodeterminación mediante un proceso pactado que resuelva el problema de un territorio y de una población. Resolución del problema a través de una decisión directa de partes -Marruecos y Frente Polisario- mediatizadas por Secretario General y Consejo de Seguridad. Vía de solución que excluía directamente a la población del territorio y al proceso de autodeterminación y descolonización, gestado durante casi mediante siglo, y al que según la doctrina que se desprende de la Carta de Naciones Unidas, Resolución 1514 y Resolución 2625, supone un derecho inalienable para el pueblo saharaui y una obligación vinculante para la sociedad internacional. Esta potencial solución ha venido inducida por los tres principales actores internacionales indirectos como son Estados Unidos, Francia y España ${ }^{43}$. Cuenta con el beneplácito de Marruecos y la oposición radical del Frente Polisario, Argelia y la O.U.A. El Frente Polisario ha mantenido en las conversaciones de Londres y Berlin (junio y septiem-

41 Este importante detalle ha sido confirmado por el coronel Emili Cuevas, uno de los autores del censo español de 1974. Cuevas proporcionaria a Naciones Unidas un código de secciones registrales de los tiempos de la presencia española para facilitar la acción administrativa pero asegura que "las autoridades de la Minurso lo adoptaron como si definiera a la población del Sahara Occidental". Los técnicos de la Minurso lo asumirian como posibles integrantes de la población del Sahara Occidental: "como en el código aparacían los grupos H41, H61, J51 y J52, la ONU consideró que todos ellos eran (podian ser) saharauis". Cuevas afirma que el error nunca fue corregido. De ejemplo cita como "la tribu Ait Bamarán, originaria de una zona cercana a Sidi Ifni, figuraba en las secciones registrales porque había 600 personas de este origen que vivian en el Sahara y estaban reconocidas como saharauis. Pero eso no quiere que todos los bamaranis sean saharauis" (El Pais, 6 de noviembre de 2000).

42 C.I.P/S.I.P, Observatorio de conflictos: Informe sobre el Sahara Occidental, Madrid, 1999.

43 El Pais, 12 de mayo del 2000; ABC, 15 de mayo del 2000. 
bre del 2000) un calendario de arreglo que no pasa sino por la continuación del proceso de autodeterminación sobre la base de los Acuerdos de Houston, y a través de un calendario especifico y riguroso para los recursos presentados por Marruecos ${ }^{44}$.

\section{MARRUECOS. LA SATRAPIA-ESTADO}

Al comienzo exponíamos el argumento según el cual diferentes Estados, politicos, medios de comunicación e intelectuales contemplaban la idea de una integración del Sahara en Marruecos merced a la dinámica ejemplar de desarrollo político y económico de ese Estado. Este capítulo va a ser utilizado para argumentar lo contrario.

En su definición más simple el concepto dictadura se opone al concepto democracia. Significa el poder sin limitación de una persona o junta sobre el Estado. Supone un orden institucional autoimplantado, provisto de legitimación y caracterización propias. Puede ser temporal o vitalicia, formalmente inconstitucional o semánticamente constitucional, militar, de partido único o de partidos. También viene calificada por el sector sociopolitico que la instrumentaliza. En este sentido Marruecos entraría de lleno en esta caracterización. Sin duda tiene Constitución pero esto no le exime de ser ente dictatorial ya que resulta tanto técnica como operativamente semántica y donde opera un sistema de partidos de retórica competitiva. Incluso las propias Constituciones de 1992 y 1996, que suponen un teórico avance respecto a los textos anteriores, mantienen el hecho de un poder real que controla los tres poderes. Capacidad para nombrar y cesar al gobierno. Capacidad para controlar la actividad legislativa y reglamentaria. Capacidad ilimitada para disolver la Cámara. Capacidad para mediatizar la tarea legislativa. Control y nombramiento de los altos órganos judiciales y del Consejo Constitucional. Y no podría ser de otra manera, ya que el rey no es un órgano más de la Constitución, sino el poder constituyente, la fuente de legitimidad de todos los textos constitucionales que, como el del 96, han sido aprobados y promulgados por dahir (decreto).

La virtualidad jurídica del autoritarismo-dahir se extiende también a la casi totalidad de la materia legislativats. El parlamento queda anulado como órgano desde el momento en que: a) el ejecutivo es nombrado por dahir y b) el legislativo puede ser disuelto en cualquier momento del mismo modo ${ }^{46}$. Lo mismo sucede respecto al nombramiento del Consejo Constitucional, cuyo control y nombramiento está en manos del monarca, como de una forma indirecta el Consejo Superior de la Magistratura cuyos miembros han sido designados por él, con lo que también de forma indirecta acaba controlando el nombramiento de todos los magistrados ${ }^{4}$. También quedan exclusivamente bajo su poder la instauración de todos los estados excepcionales, la declaración de guerra y la firma de tratados interna-

44 Para todos los detalles juridicos en relación con los aspectos problemáticos de esta segunda fase vease el epígrafe I de este trabajo.

45 Salvo nueve competencias de exclusiva competencia del Parlamento (art. 46)

46 Arts. 24 y 27.

47 Arts. 30, 79, 84, 86. 
cionales $^{48}$. Por si quedara alguna duda sobre cual es el centro único de irradiación del poder, la inmunidad parlamentaria no alcanzará a "las opiniones que cuestionen el régimen monárquico $o$ atenten contra el respeto debido al rey" '99. Respecto a derechos y libertades la que se supone exitosa Constitución democrática hace una exigua consideración de los mismos, quedando reducidos a su somera enunciación en ocho artículos que pueden quedar recortados o anulados por una simple mención de la ley. Derechos desprovistos de todo tipo de enunciado y mecanismo garantista ${ }^{50}$. En teoría general de la Constitución hay un presupuesto básico: sin tutela y garantias efectivas de los derechos fundamentales no hay Constitución, sólo hay autoritarismo y dictadura.

Toda la apropiación real sobre el ejecutivo y la administración, la capacidad de control y disolución del legislativo y la mediatización sobre las instancias judiciales impide que toda la enunciación de derechos individuales, que hace la carta constitucional, quede inoperativa, tal y como demuestran los diversos informes sobre la situación de los derechos humanos y la ausencia de las más elementales garantías judiciales. Marruecos sigue siendo un pais con detenidos arbitrarios, torturas, juicios sumarios, formaciones políticas ilegales y prisioneros políticos. Situación que se sigue manteniendo en lo sustancial desde la entronización del nuevo monarca, no sólo según el reciente informe de Amnistía Internacional, sino del nada sospechoso Bureau of Democracy, Human Rights and Labor del Departamento de Estado estadounidense ${ }^{5 l}$. Citando informaciones de la última semana podemos contemplar la expulsión del delegado de France Presse. Su delito habría sido difundir la carta abierta enviada por la Asociación Marroquí de Derechos Humanos, en donde se informaba de los nombres de funcionarios que siguen ejerciendo importantes responsabilidades a sabiendas de su implicación en violación de derechos humanos referentes a desapariciones, torturas y encarcelamientos arbitrarios. Medida sobre la que han guardado silencio los autodenominados principales partidos políticos democráticos ${ }^{52}$.

La cuestión estrictamente política tiene su lógico correlato en el ámbito de clanes que es favorecido por la estructura dictatorial. El rey no es la dictadura, sólo la representa y es su máximo exponente y ejecutor. Alrededor se dibujan una serie de círculos concéntricos administradores y beneficiarios. Es el Makhzen. Toda una red de intereses económicos y

48 Aits., 35, 49, 74, 33.

49 Art. 39.

50 Arts 8 a 15. La limitación de los derechos por una simple ley incluso para las libertades más básicas del art.9.

51 Ref. 1999 Country Reports of Human Rights Practices. Respecto a los informes de Amnistia Internacional, en especial seria muy significativo el monográfico de Amnistía Internacional (sección española), Marruecos: detenciones politicas, desapariciones y torturas, Madrid, 1991. Probablemente, respecto a las anteriores décadas, la represión no ha empeorado pero los últimos informes de Amnistia Internacional 1998, 1999 y 2000 han sido igualmente severos. Cientos de personas llevan decenas de años en las cárceles por simples delitos de opinión. Sirva el dato de como ya con Mohamed VI en el poder, a finales de 1999, 25 saharauis fueron condenados a 25 años por manifestarse a favor de la autodeterminación y en contra del estado de sitio impuesto por Rabat. (El Pais, 9 de noviembre de 1999).

52 El Pais, 5 y 7 de noviembre de 2000. Los casos se pueden multiplicar, y asi H. Amraoui, director del diario Fossoul Asilah se enfrenta a peticiones de carcel y cierre del diario hechas directamente por el ministro de Asuntos Exteriores por el hecho de dar datos y pruebas sobre corrupción en instancias nacionales y locales (El Mundo, 12 de noviembre de 2000). 
posicionamiento social basados en pleitesías y servidumbres totales escalonadas jerárquicamente. El escalonamiento jerárquico se corresponde también con los niveles de fortunas millonarias creadas al amparo de una corrupción general de la clase dirigente y cuyo principal exponente es la incalculable fortuna de palacio ${ }^{53}$. Las grandes fortunas se sirven directa $o$ indirectamente de todo el sector industrial, comercial y financiero público de donde extraen los recursos para incrementar sus patrimonios y sus depósitos en el extranjero. En definitiva la oligarquización política institucionalizada encubre toda una red cleptocrática añadida ${ }^{\text {st }}$ Makhzen del que también participan los principales partidos políticos. Partidos cortesanos. Cómplices de una dictadura porque sólo se puede llamar cómplice a una cohabitación de décadas que elimina la más mínima intención de posibilismo democrático. Dirigentes del partido liberal-nacionalista Istiqlal, liberales independientes o, en los últimos años, del socialista USFP han compartido durante años consejo de ministros con el monarca absoluto Hassan II. Han gobernado, por decreto, al dictado del makhzen en el que se integrarian como un clan más. Conglomerado del que es imposible resulte un proceso de transición y definición democrática, puesto que los cambios formales e incluso institucionales se generan como un recurso del sistema para asimilar e integrar los cambios ${ }^{5 s}$.

El negativo balance político anterior podría quedar matizado si los indicadores economicos y sociales nos dieran un balance positivo. Sin embargo, Marruecos no consigue salir de una situación de miseria grave, con unas tasas de analfabetismo, enfermedades crónicas, mortalidad o deficit alimentario a la altura de los paises africanos peor situados. Su situación en los indicadores de desarrollo humano y de pobreza está a niveles tan bajos que su IPH (38.1) sólo es superado en el mundo por veintinueve Estados de ciento setenta y cuatro. Paises como Ruanda, Nigeria, Zambia o India dan resultados menos negativos según el PNUD $^{s 6}$.

Otros organismos sitúan a Marruecos en el $45 \%$ de la miseria absoluta (BIRD),y según la OMS la mayoría de la población sufre malnutrición. El $25 \%$ de la población urbana vive en los arrabales miserables de las ciudades (brariks), donde la densidad de la población es de mil habitantes por hectárea sin agua, electricidad y ni siquiera cloacas. En función de su conflictividad política o social (revueltas de 1965, 1981, 1989), periódicamente, estos arrabales son destruidos, parte de su población detenida y el resto desalojados. Desde 1989, los suburbios de Rabat, Fez, Meknés fueron limpiados y sus poblaciones desalojadas ${ }^{57}$.

53 Incalculable incluso para los estudios especializados que la cifran en alrededor de treinta mil millones de dólares a través de una intrincada red de sociedades y testaferros (cfr. P. BEADEUX, Les plus grandes fortumes du monde, Paris, 1988).

54 El caso del ONA (Omnium Norte Africano), SOFIPAR y grupo Kettani. $Y$ todo un entramado descrito en la segunda parte del libro de M. DIOURI, A qui appartient le Maroc?, Paris, 1991.

55 Cfr. para una análisis detallado M. A. PAREJO, Las elites políticas marroquíes, Madrid, 1999.

56 P.N.U.D., Informe sobre desarrollo humano 2000, Madrid 2000.

57 “¿La destrucción de los arrabales? Es una política de tierra quemada aplicada a los más pobres... Encaramado a una pared de la vergüenza como hay tantas en la periferia de las ciudades marroquíes, Jawad, un maestro de 39 años, realiza esta observación como una evidencia" (Le Monde, 22 de enero, 1990, cit. M. DIOURI, $A$ qui appartient ..., op. cit., pp. 249 y ss). 
En función de todas las variables descritas, cualquier parecido de la realidad presente de Marruecos -política, económica y social- con la aséptica imagen de modernidad, desarrollo y democracia con la que se asume en un mayoria de medios políticos y de comunicación occidentales no sólo no es pura coincidencia sino que entraña unos preocupantes niveles de manipulación politica.

\section{POLÍTICA INTERNACIONAL DE ESTADO VS. POLÍTICA INTERNACIONAL DE DERECHO}

\subsection{La posición de España y Francia}

Los juegos de poder de España, y un claudicante sentido de las relaciones exteriores, dejaban en 1975 a una población total de cien mil personas (más de doscientas mil en 1999), en el exilio o a merced de la ocupación militar de una dictadura. Población de lengua española, con pasaporte y nacionalidad española, con representación en Cortes y cuyo territorio era una provincia propia más desde la perspectiva administrativa.

Este elemento político-administrativo junto con los materiales expuestos desde la perspectiva histórico-cultural deberían haber avalado una posición de España inequivocamente a favor de la independencia del territorio. Sin embargo, el resultado ha sido el contrario.

Durante todo este tiempo la actitud de los sucesivos gobiernos españoles ha sido la de un apoyo formal y verbal a las resoluciones de Naciones Unidas, y a la vez la de un apoyo efectivo al régimen marroquí. El régimen de Hassan II ha tenido un trato preferencial en politica crediticia, comercial, de inmigración y pesquera. Los acuerdos de pesca han reportado a Marruecos 20.000 millones de subvenciones más los cánones de los armadores. Lo más grave de este capítulo es que una gran parte de las capturas se desarrolla sobre el banco pesquero sahariano, cuya explotación en ningún caso ha sido cedida por España, a no ser que se le diera una interpretación muy favorable a los mencionados Acuerdos de Madrid, cosa no posible por ser nulos de pleno derecho desde la perspectiva jurídica internacional. Esta explotación pesquera contraviene el reconocimiento que el Derecho Internacional otorga a los territorios no autónomos sobre sus recursos naturales, según se puede desprender desde el propio artículo 73 de la Carta de Naciones Unidas a la III Conferencia de Montegobeille (1993) ${ }^{\text {s8 }}$.

En un segundo capitulo a Marruecos se le conceden subvenciones y créditos blandos a cargo de los Fondos de Ayuda al Desarrollo (FAD). Exactamente recibiria 18000 millones entre 1980 y 1990 de 50.000 millones totales presupuestados para toda la ayuda. Lo más grave sería como se prestaban esas cantidades a un país inserto de lleno en la miseria, para mantener una guerra con los propios colectivos saharauis desplazados. El Estado español habria estado prestando miles de millones para armamento a sabiendas de que iba a ser uti-

58 En referencia a la Conferencia sobre Derechos del Mar celebrada en Jamaica. Las obligaciones para Estados administradores se reflejan también en múltiples disposiciones como la ya citada Res. 1514 (o antecedentes como las Res. 648 y 742). Compárese al respecto la normativa respecto a los casos de Namibia y Sudáfrica. 
lizado contra los propios saharauis expulsados, durante todos los años de la década de los ochenta que duró el conflicto. Hay un último elemento más grave: una parte del armamento utilizado era vendido por España a través de la entonces empresa pública Santa Barbara ${ }^{59}$.

Esa política de apoyo explícito a Marruecos no ha sido casual sino que ha sido asumida conscientemente por los sucesivos gobiernos de UCD, fundamentalmente por los del PSOE y continuada por los del P.P. La primera visita de todos los presidentes del Gobierno, recién investidos, es a Rabat. Sin excepción. En su visita hablan de cooperación, amistad tradicional y otros tópicos al uso que luego revierten en acuerdos que estabilizan al régimen, sin exigir a cambio una reestructuración política, económica y social real. Línea continuada por parte de todos los ministros de asuntos exteriores, incluidos aquellos que más se habían destacado con anterioridad en la defensa de la autodeterminación saharaui como sería el caso de Morán ${ }^{60}$. En esta política no sólo saldría beneficiado el régimen marroquí sino perseguido administrativamente, dentro de las fronteras españolas, el propio Frente Polisario cuya representación diplomática sería expulsada en 1985. En coherencia con esa estrategia se ha denegado la práctica totalidad de estatuto de refugiado político a saharauis procedentes de los territorios ocupados o del propio Marruecos. Por contra, las visitas a Marruecos de las más altas magistraturas de la Nación, como las del Rey o el Presidente del Gobierno, han sido periódicas. Exactamente nuestra jefatura del Estado mantiene unas estrechas relaciones familiares y de amistad. Hay que recordar que nuestra representación institucional y diplomática para las exequias de Hassan II ha sido la más alta en la historia de la diplomacia española. La actitud de nuestra diplomacia raya en la pleitesía cuando no hay gobernantes tan condecorados por el protocolo español como los pertenecientes a la satrapía marroquí. Un ejemplo, que merece algo más que un pie de página, sería la condecoración de toda la delegación marroquí en septiembre de 1989: Hassan II, collar de la Orden de Alfonso X el Sabio; Príncipe Moulay Rachid, collar de la Orden del Mérito Civil; Princesa Hasnaa, banda de la orden de Isabel la Católica; General ayudante de campo de Hassan II, Abdelkader Loubarriz, gran cruz de la Orden del Mérito Militar; Secretario general de Defensa, Mohamed Achahbar, gran cruz de la Orden del Mérito Naval ${ }^{61}$.

Francia es el primer país europeo en sus niveles de ayuda económica y colaboración con Marruecos. El apoyo de Francia no es a Marruecos como Estado sino al propio régimen y, más concretamente al propio makhzen. Se han demostrado altos niveles de imbricación económica entre empresas francesas y el makhzen. Empresas francesas que amparan y se lucran de la apropiación del Estado y las riquezas del país por esa clase gobernante. En ese conglomerado de intereses la clase política mantiene un tono de apoyo al régimen de lo que es buena prueba su apoyo casi explícito a la integración del Sahara en Marruecos. Buena

59 TRIBUNAL DE CUENTAS, Informe de fiscalización del fondo de ayıda al desarrollo, varios años.

60 "No solamente no haremos nada para desestabilizar al rey de Marruecos, sino que realizaremos todo lo que esté en nuestra mano para mantener su estabilidad" (30 de noviembre de 1982). Compárese el cambio radical en la perspectiva del análisis respecto a su "prólogo" al libro de F. VILLAR, op. cit., pp. 11-16, de fecha 5 de enero de 1982.

61 Para un análisis periodístico exhaustivo, cfr. Cambio 16, "Nuestro amigo el tirano", 8 de abril de 1991, $\mathfrak{n}^{\circ}$ 1.011 , pp. 10-26. 
prueba son sus intervenciones diplomáticas en los foros internacionales. El caso de Marruecos resulta muy especial porque incluso unos medios de comunicación franceses, habitualmente muy críticos en política internacional, no mantienen apenas fisuras en su tratamiento amable del régimen marroquí salvo excepciones puntuales como el caso reciente de France Presse. En el caso francés resultó todo un acontecimiento el libro del periodista Gilles Perrault descubriendo toda la trama que vinculaba a las elites francesas con el makhzen ${ }^{62}$.

\subsection{Las siniestras estrategias de la lógica mercantil}

Este despliegue en el agasajo, en el que no sólo entran ventajosos acuerdos económicos, de los que se lucran las elites marroquies, sino toda una exhibición premial tercermundista, resulta más duro cuando hay que recordar que 1989 era un año donde se estaba combatiendo a la resistencia saharaui y sembrando de minas antipersonales toda una línea de demarcación. Año en el que se recrudecían los informes de Amnistía Internacional respecto a presos políticos, desaparecidos y encarcelados, y que venían corroborados por las resoluciones del Parlamento Europeo denunciando la violación de los derechos humanos en Marruecos y condenando la represión en las zonas ocupadas ${ }^{63}$. Sólo un año después de tamaña exhibición premial, Amnistía Internacional publica tres demoledores documentos. Un primer documento (septiembre de 1990) "Marruecos. Desapariciones de saharauis occidentales"; un segundo y tercer documentos (marzo de 1991) "Marruecos. Represión y venganza de Estado" y "Marruecos. Detenciones politicas, desapariciones y torturas" ${ }^{4}$. En medio de la publicación de los dos documentos (diciembre de 1990), el Presidente del Gobierno, Felipe González, visitaría a Hassan II firmando convenios y créditos por 150.000 millones pesetas ${ }^{65}$.

Saltando en el tiempo diez años adelante las mismas actitudes de política exterior siguen permaneciendo. El presidente Aznar, tras sus dos investiduras (1996 y 2000), ha desarrollado idéntico ritual : a) la primera visita la ha efectuado a Rabat; b) ha firmado convenios de cooperación y avalado créditos de importantes cantidades; c) no realizó ningún juicio crítico ante la actitud de Marruecos que, tras la firma de concesión de los caladeros pesqueros marroquies y saharianos a varias multinacionales holandesas, ha dejado a mil familias españolas paradas y a cargo de las dotaciones mensuales de un fondo especial de los presupues-

62 G. PERRAULT, Nuestro amigo el rey, Madrid, 1991. Perrault es prestigioso escritor de investigación francés. Su libro hizo dueto con el de Diouri poniendo al descubierto todo un entramado de intereses y complicidades.

63 Resoluciones del Parlamento Europeo de 14 de mayo y 17 de diciembre de 1987.

64 Todos ellos publicados por la sección española de Amnistía Internacional a fechas de 1990 y 1991

65 La actitud de los gobjernos socialistas resulta de mucho más contraste teniendo en cuenta los antecedentes programáticos y prácticos del PSOE. Desde el primer viaje del hoy presidente González a Tinduf, el 14 de noviembre de 1976, donde González firmaría en los campamento de refugiados de Tínduf, una declaración conjunta PSOE-Frente Polisario, en la que se denunciaban los acuerdos de Madrid y se pedia la autodeterminación del pueblo saharaui. Declaración bajo el exordio, posteriormente falso, de Felipe González: "Sabemos que vuestra experiencia es la de haber recibido muchas promesas nunca cumplidas: yo quiero por consiguiente no prometeros algo sino comprometerme con la Historia: nuestro partido estará con vosotros hasta la victoria final". Comunicado que se repetiria, de manera incluso más completa, el 8 de septiembre de 1977. 
tos del Estado español (además de todos los sectores productivos indirectamente afectados); d) tampoco parece lo suficientemente relevante al gobierno español que los territorios ocupados del Sahara occidental sigan cerrados para los medios de comunicación españoles y asociaciones de derechos humanos; e) a mayor abundamiento Marruecos es Estado líder en el cultivo y exportación de estupefacientes, donde está probada la participación de los grupos predominantes en el makzen y del propio palacio. Calculándose que es la primera fuente de divisas con 700000 millones de pesetas ${ }^{66}$. Toda una actitud de muy amplia benevolencia que no pareció impresionar al primer ministro socialista Yusufi que se tomaria la libertad de reprender al presidente del gobierno español, criticando el reciente proyecto de ley sobre inmigración y los malos tratos y vejaciones dados a la población marroqui inmigrante. Ejercicio de cinismo político ante el que el presidente Aznar permaneció pasivo.

$¿$ Que razones puede haber para que dos paises -tres si consideramos el papel de Estados Unidos- inscritos en la teórica órbita de los respetos a los derechos humanos y la promoción de la democracia, como imperativos categóricos de sus políticas, apoyen incondicionalmente a una dictadura? ¿A un Estado que ha estado violando sistemáticamente todos los derechos humanos, reprimiendo con la muerte, la desaparición o la cadena perpetua familiar cualquier tipo de oposición? ${ }^{67}$ ¿A un ejercito de ocupación que mantiene un territorio ocupado en estado de guerra con todos los derechos anulados, y que obstaculiza permanentemente a los representantes del máximo organismo internacional? Un apoyo que, pese a la desprotección militar de la parte más débil, el Frente Polisario, llega a vender millones de dólares en armamento para la máquina de guerra marroqui. Millones de dólares que salen de las arcas de los fondos de ayuda al desarrollo europeos, de los créditos de ayuda al desarrollo proporcionados por el Estado español, o de los leoninos cánones para la explotación pesquera del propio banco sahariano. Ayuda al desarrollo para vulnerar militarmente planes de paz y resoluciones del más alto organismo mundial, créditos blandos para alimentar un sistema policial que engorda año tras año los informes de Amnistía Internacional, y convenios de pesca que burlan el derecho que la normativa internacional reconoce a los territorios no autónomos, sobre sus recursos naturales.

Un apoyo que no sólo es directo sino que se bate a favor de la satrapía marroquí incluso en los foros internacionales donde se es menos condescendiente, como han sido los casos de luchas contracorriente en el Parlamente Europeo, de Francia y España, para levantar votaciones negativas a Marruecos para la concesión de miles de millones de los fondos comunitarios al desarrollo. Millones de dudosa utilización para programas de desarrollo, teniendo

66 Generados directa e indirectamente por todo el mercadeo (estructura de cultivo y comercialización corroborados por el informe del Observatorio Geopolítico de Drogas y la unidad de estupefacientes de la secretaría general de la Comisión Europea, Rapport d'enquete sur les enjetux politiques, economiques et sociaux de la production et du trafic des droques au Maroc, París, 1994).

67 Lo de cadena perpetua familiar es un tipo de pena inédito para el derecho penal, pero en cuya acuñación práctica se ha ejercitado a conciencia la satrapía marroquí. En Marruecos en ocasiones no sólo se ejecutaba, hacia desaparecer o encarcelaba al disidente sino que la pena alcanzaba a toda su familia, e incluso amigos, que eran encarcelados de por vida. El caso más llamativo, conocido por toda la sociedad internacional -incluidos los gobiernos de España y Francia- es el del penal de Tazmamart 
en cuenta lo divulgado en los trabajos de investigación sobre su régimen por Perrault o Diouri, donde las fronteras entre los presupuestos y las empresas del Estado marroquí se confunden con los beneficios y las empresas de las grandes familias allegadas a la corte.

Como argumentos para explicar lo anterior no valen la promoción de los derechos humanos ni el tránsito a la democracia. Eterna transición a la democracia, eterna mejora de los derechos humanos y eterna modernización que no resisten el más mínimo análisis. Transición democrática que choca con el espiritu de la novísima Constitución de 1996 y todo el inamovible marco institucional. Constitución de legitimidad monárquica, ausencia de separación de poderes y concentración del poder en manos del autócrata. Derechos humanos que chocan con los mencionados informes anuales de Amnistía Internacional, del Departamento de Estado U.S. y del propio Parlamento Europeo. Modernización que supone una burla cuando año tras año la cleptocracia marroquí absorbe los millones de dólares de ayuda y deja a su país en los últimas posiciones del mundo en tasa de miseria y proporción de pateras.

Tampoco sirve el argumento basado en el discurso bipolar de la guerra fría sobre zonas de influencia irrenunciables que ya no existen (¿no existen?).

$¿ \mathrm{Y}$ que razones diferencian al régimen de Marruecos respecto a otros paises con índices económico-políticos mucho menos perversos, y que sufren actitudes de crítica permanente, negativa a la colaboración o incluso de bloqueo explícito? ¿Que pueden tener Libia, Cuba o Irán que no tenga Marruecos?

Sin duda debe haber otros motivos para ese apoyo. Motivos que versan más sobre la llamada razón de Estado que sobre democracia o derechos humanos. En primer lugar la consideración mercantilista sobre las grandes posibilidades de negocio y de inversión neocolonial. ¿Neocolonial? Si, Marruecos es país con mano de obra barata, sindicatos-makhzen y nulo sistema impositivo sustituido por los cánones al propio makhzen. Situación que ya ha comenzado a ser aprovechada por medianos empresarios aventajados y, sobre todo, por grandes empresas, como varias de las procedentes de los recientes procesos de privatización como son los casos de Telefónica (monopolio de la telefonía móvil a través de Medi Telecom) y el sector eléctrico (la posición preeminente de ENDESA). En segundo lugar la intrincada red de intereses que vincula a empresarios y políticos franceses y españoles con los intereses de palacio y de industriales y políticos marroquíes. Sin la que es imposible explicarse el apoyo incondicional que en Francia se le aplica a un régimen autoritario ${ }^{68}$. En tercer lugar la propia debilidad de diplomacias como la española, temerosa y titubeante ante

68 Al respecto los libros citados de Perrault o de Diouri. Aunque este último es dificilmente encontrable ya que la maquinaria de presión de Marruecos consiguió que el libro se viera envuelto en varios procedimientos judiciales y administrativos, manteniendo el Estado de Marruecos toda una serie de presiones y amenazas ante las más diversas instancias desde editoriales a la presidencia de la República.. Incidentes inéditos en el país del mundo donde los límites de la libertad de expresión están más altos. No sólo eso sino que Diouri fue deportado a Gabón a través de un procedimiento administrativo fulminante, ejecutado por la administración de Michel Rocard e instado por el lobby político y administrativo promarroqui. Lobby que agrupa a una buena parte de las clase política, económica y mediática francesa. Finalmente tuvieron que ser sucesivos autos y sentencias judiciales las que devolvieran al escritor a Francia (véase el "Preámbulo" a su libro del propio Diouri). 
el chantaje permanente respecto a las plazas de Ceuta y Melilla. Respecto a Francia también son clásicos anclajes de su política exterior, acostumbrada a anudar histriónicas actitudes de condena por violación de derechos humanos con episodios de apoyo a las más violentas dictaduras. Actitud de décadas, por la que no debe extrañar la actitud combativa de Mitterrand contra el pueblo saharaui, pues ya Mitterrand firmaba en 1956 el famoso decreto que mandaba a la guillotina a los resistentes argelinos, bajo el tutelaje de tribunales de justicia militar sumarísima. Es la vieja historia de apoyo a sátrapas del estilo de Bangui, Mobutu, Abidjan. La historia del petróleo gabonés o del uranio nigeriano. Es la vieja razón de las materias primas baratas, de las industrias propias subvencionadas, de la deuda exterior impuesta. Es una simple permanencia del esquema neocolonial.

Estrategias realistas de política exterior fatales que se acaban convirtiendo en sinónimo de simbiosis con dictadura y de abandono de una política que prime por encima de cualquier consideración el respeto a los derechos humanos, a la declaración universal y a la normativa internacional de apoyo. Una prueba mas de que la democracia, los derechos humanos y el desarrollo no terminan nunca de abrirse hueco en todo el miserable ámbito periférico por las estrategias geomercantiles de los propios paises occidentales, habitualmente adornadas por los que se demuestran falaces discursos sobre desarrollo. Estrategias que en los casos más graves acaban produciendo conflictos en vez de evitarlos.

Precisamente en la dialéctica que enfrenta a Marruecos y al Frente Polisario, la guerra fue una realidad y puede volver a serlo ¿Que sucederá si el Consejo de Seguridad o el Secretario General de N.U., inducidos por las diplomacias de Francia, Estados Unidos y España, finalmente adoptan resoluciones en el sentido de aceptar las tesis marroquíes sobre el aumento indiscriminado del censo, o bien abren la llamada tercera vía de integración? La diplomacia saharaui ya ha comentado entre bastidores sobre una posible inevitabilidad del conflicto armado. Afirman estar mejor preparados bélicamente que en 1975. Sus hombres llevan movilizados militarmente todo ese tiempo. En la situación actual al Frente Polisario, reconocido y apoyado políticamente por decenas de Estados, no le resulta complicado acceder al mercado de armas. El retorno a la lucha armada no es sino la opción considerada en función de que a Occidente lo único que le puede inducir a respetar el derecho a la autodeterminación y a considerar el sufrimiento de una tierra bajo ocupación militar es la de una posible desestabilización de la zona. Por lo que supondría de costes económicos e incluso políticos.

\section{LA OTRA CARA DEL MARCO INSTITUCIONAL. EI PAPEL DE LA CLASE POLÍTICA PERIFÉRICA Y LA SOCIEDAD CIVIL}

En España la falta de voluntad en la clase política dirigente por considerar los factores democracia, derechos humanos y legalidad internacional ha tenido una cara contraria en los tramos de clase política instalados a nivel autonómico y local. De la misma forma todos los segmentos de sociedad civil representados por ONGs y sindicatos han ofrecido un apoyo incondicional a la causa del referéndum, de crítica al régimen marroquí y de apoyo al Frente Polisario. Organismos periféricos y ONGs han sido agentes fundamentales para el manteni- 
miento de los campamentos de refugiados en Tinduf. Los constantes proyectos de ayuda alimentaria, sanidad, material escolar, transporte o infraestructura varia, sin los que una mínima vida digna y organizada no hubiera sido posible.

En las posiciones estrictamente politicas ha habido una casi unanimidad en la clase politica. Un ejemplo lo tenemos en los comunicados emitidos por la gran mayoria de parlamentos autonómicos. En todos ellos hay un apoyo al referéndum, una denuncia a la actuación obstruccionista de Marruecos y una demanda al Gobierno español y a la Unión Europea para un papel más activo. En este sentido es muy representativa la Declaración de la $5^{a}$ Conferencia de los intergrupos parlamentarios "Paz y libertad en el Sahara Occidental"'s9. Eso en cuanto a las cámaras legislativas representativas del ámbito autonómico. Pero los contundentes comunicados no han sido sólo obra de los poderes legislativos sino que han ocupado a todos los ámbitos de la representación politica y sindical, y un buen ejemplo lo tenemos en el manifiesto signado en la Comunidad Autónoma de Aragón. Este Manifiesto sería firmado por el Presidente de la Comunidad Autónoma, el Presidente de las Cortes y los alcaldes y presidentes provinciales de las tres provincias; es decir la totalidad de la representación política autonómica y local sin excepción, incluidas las fuerzas minoritarias menos representativas ${ }^{70}$. En este caso el manifiesto también hacia alusión directa y contundente a las obstrucciones y violaciones del Estado de Marruecos y a las responsabilidades españolas aun no dirimidas" ${ }^{7}$. Tanto en la actitud del grupo interparlamentario como

69 La Declaración afirma textualmente: "se muestra vivamente preocupada por la represión ejercida contra la población saharaui por las autoridades marroquies en las últimas semanas en diversas ciudades del territorio(...)Apela a la ONU para que proteja a la población saharaui y presione a Marruecos para que vuelva la normalidad al Sahara y el diálogo sustituya a la fuerza(...)Hace un llamamiento a las organizaciones de defensa de los derechos humanos para que intervengan ante las autoridades marroquies a fin de evitar que se violen los derechos más elementales de la población saharaui(...)demanda igualmente la apertura de los territorios ocupados a la comunidad y prensa internacional(...)Acuerdan rechazar otras förmulas no contempladas en el Plan de paz y en los acuerdos de Houston, que sólo pretenden ganar tiempo y distraer la atención y que no conducirán a una solución del conflicto(...)Denunciar los nuevos obstáculos del Gobierno de Marruecos, mediante la presentación de miles de apelaciones, para impedir la aplicación de los acuerdos suscritos por las dos partes y la celebración de la consulta..." (Declaración de la $5^{a}$ conferencia de los intergrupos parlamentarios "paz y libertad en el Sahara occidental", Palma de Mallorca, 31 de marzo del 2000).

70 Así el elenco firmante incluia a PP, PSOE, CHA, PAR e IU. Representación politica que se completaba con la adhesión de todos los sindicatos, Universidad de Zaragoza, Colegio de Abogados, Seminario de Investigación para la Paz, Centro Unesco y Federación de barrios. Además de ser respaldado por la Ascociación de la Prensa. $Y$ avalado por una selección representativa de artistas y escritores.

71 Alegaba entre otras cosas: "la gravedad de una potencial coyuntura de guerra abierta en el Sahara Occidental(...)que el pueblo saharaui lleva exiliado 25 años(...)Su territorio fue cedido a Marruecos que lo ocuparía militarmente, apropiándose de sus recursos y eliminando o encarcelando a todo el que se opuso a la invasión según reiteradas denuncias de Amnistía Internacional. La milad de la población saharaui huyó a través del desierto refugiándose en el desierto argelino. Cientos de saharauis morirían en la guerra de resistencia. El resto de la población quedaría sujeta a todas las privaciones, inmovilizada en medio de la dureza del desierto y separada durante décadas de sus familiares y amigos(...)Todas las resoluciones de Naciones Unidas desde 1963 reconocen su estatus de territorio no descolonizado y apoyan la autodeterminación. El Tribunal Internacional de Justicia (1975) dictıminó sobre la no pertenencia histórica, politica o cultural del territorio a ningún Estado. Naciones Unidas ha retrasado durante diez años el referéndum por negarse Marruecos a aceptar como base el censo español de 1974 e incluso las conclusiones del Comité de Identificación de Naciones Unidas. Por todo ello, teniendo en cuenta todas las graves responsabilidades contraidas por España con ese pucblo - $\mathrm{y}$ aun no dirimidas- los abajo firmantes solicitan de las instituciones nacionales hacer todos los estuerzos posibles para que el referéndum se lleva a cabo según el censo propuesto por la Comisión de Identificación 
en el caso concreto de los manifiestos interinstitucionales vemos que el tema del referéndum del Sahara es el único tema de política nacional e internacional en el que hay unanimidad de todo el arco parlamentario, sin excepción, y de toda la clase sindical, prescindiendo de las equívocas y tibias posturas de la clase politica central y de las ejecutivas de los dos principales partidos.

Algo similar ocurre en le ámbito de la sociedad civil organizada. ONGs vinculadas parcialmente a partidos políticos concretos han desarrollado modelos de apoyo contundentes a favor del Frente Polisario y de denuncia al régimen marroquí. El mejor ejemplo del contraste podría ser el Movimiento por la Paz-MPDL, organización muy vinculada al PSOE, y que lleva efectuados cientos de proyectos emprendidos de apoyo a los campamentos de refugiados de Tinduf. Otros ámbitos de la sociedad civil como los colegios profesionales de abogados o la Universidad han prestado su apoyo en forma de becas para estudiantes saharauis o en la denuncia de la situación judicial en los territorios ocupados ${ }^{72}$.

\section{CONCLUSIÓN. LÓGICA GEOECONÓMICA O LÓGICA JURÍDICA}

En estos meses, en los que Marruecos bloquea el cumplimiento de los Acuerdos de Houston, parecen querer abrirse posiciones neoasimilacionistas denominadas de "tercera vía". Es la propuesta que se va a llevar a las conversaciones de Londres (Junio del 2000). Resultaria paradójico que cuarenta años después de la primera resolución de Naciones Unidas, favorable a la autodeterminación del territorio, se retornara a la doctrina Kissinger, sobre el Sahara Occidental, por la que el territorio debía pasar a Marruecos mediante conversaciones y con preferencia a la aplicación de la doctrina de Naciones Unidas. La "tercera vía" baraja la opción de la integración con autonomía o la partición del territorio. Eso parece ser lo sugerido tanto por el Secretario General de N.U. como por su enviado especial Baker. También es la postura que parecen avalar los gobiernos estadounidense, español y francés ${ }^{73}$. No serian sino remedos del realismo político kissingeriano, impropios para lo que se pretende un nuevo orden internacional basado en un orden juridico a consolidar. Todas estas opciones chocan contra el proceso de autodeterminación y se justifican, una vez más, por la lógica económica más prosaica y el desprecio más elemental a situaciones directamente atentatorias a los derechos humanos. Si está solución termina por imponerse tendremos un ejemplo más para afirmar que el nuevo orden internacional no sólo no está por consolidar sino por construir. No existe. Y la consecuencia más directa cuando el orden

de Naciones Unidas. Sin aceptar presiones ni dilaciones interesadas de otras partes que no sean los propios hombres y mujeres saharauis...." (publicado el 25 de mayo del 2000 en El Periódico de Aragón).

72 Sirva como referencia el escrito tramitado por el Colegio de Abogados de Zaragoza (25 de mayo del 2000) al primer ministro de Marruecos y con copia referenciada al jefe de Estado de Marruecos, a su ministerio de Justicia y al ministro español de Asuntos Exteriores. De mayor calado es la tramitación actual en el Consejo General de la Abogacia de un pliego de información al Estado de Marruecos, interesándose por la suerte de diversos detenidos y desaparecidos saharauis.

73 El Pais, 12 de mayo del 2000; ABC, 15 de mayo del 2000. 
jurídico y las legitimidades derivadas no existen, es el estado de naturaleza. $Y$ en el estado de naturaleza todo puede valer. Incluso la guerra. $Y$ los culpables no serán las víctimas del exilio y la ocupación militar, con cuarenta años de espera para la articulación política definitiva de una razón jurídica atribuida y legitimada desde la Carta fundacional de Naciones Unidas. 